\title{
Efficacy and tolerability of a large scale change in regimen from latanoprost to travoprost in glaucoma patients at the Manhattan Veterans Administration Hospital
}

\author{
Edmund P Farris \\ New York University, New York, NY; \\ Manhattan Veterans Administration \\ Hospital, New York, NY; New York \\ Medical College, Valhalla, NY, USA
}

Correspondence: Edmund P Farris 688 White Plains Rd \#224, Scarsdale, NY 10583, USA

Tel + I 9147255556

Fax + I 914725 5597

Email idoc105@optonline.net
Objective: This retrospective study was designed to investigate the efficacy and tolerability of travoprost $0.004 \%$ substituted for latanoprost $0.005 \%$ in glaucoma patients at the Manhattan Veterans Administration Hospital.

Research design and methods: We conducted a chart review of patients with stable intraocular pressure (IOP) undergoing a formulary change in regimen from latanoprost $0.005 \%$ to travoprost $0.004 \%$. Diagnoses included primary open angle glaucoma, ocular hypertension, pigment dispersion glaucoma, and pseudoexfoliation glaucoma.

Main outcome measures: The primary outcome measures were IOP change between baseline and 6 months and patient-reported adverse events throughout the study.

Results: In the single therapy group ( $\mathrm{N}=60$ eyes), the mean baseline IOP on latanoprost was $15.8 \mathrm{mmHg}$; after 6 months on travoprost, it was $14.9 \mathrm{mmHg}(\mathrm{p}<0.1)$. In the concomitant therapy group ( $\mathrm{N}=126$ eyes), the mean baseline IOP was $16.7 \mathrm{mmHg}$; after 6 months on travoprost, it was $15.9 \mathrm{mmHg}(\mathrm{p}<0.01)$. A reduction of IOP $\geq 3 \mathrm{mmHg}$ occurred in 28 eyes of 21 patients at 6 months. An increase of IOP $\geq 3 \mathrm{mmHg}$ occurred in 5 eyes of 4 patients at 6 months. One patient was switched back to latanoprost due to irritation at 3 months. No other patient-reported adverse events, including increased hyperemia, were observed throughout the follow-up period.

Conclusions: A change in therapeutic regimen from latanoprost $0.005 \%$ to travoprost $0.004 \%$ maintained IOP control in stable patients, and in some produced a further reduction in IOP. A change in therapy from latanoprost to travoprost was effective and well-tolerated for the glaucoma patients in this study.

Keywords: glaucoma, intraocular pressure, prostaglandin analogue, retrospective studies, travoprost, latanoprost

\section{Introduction}

Prostaglandin analogues (PGAs) comprise one of the drug classes used in treating glaucoma. These agents act primarily by increasing uveoscleral outflow and thereby lowering IOP (Crawford and Kaufman 1987; Gabelt and Kaufman 1989; Nilsson et al 1989; Camras 1995). Frequently, glaucoma studies that have evaluated PGA substitutions have been conducted on patients who were poor responders to the first medication(s) (Williams 2002; Kaback et al 2004; Gandolfi and Cimino 2003; Hollo et al 2005). A recent study (Law et al 2005) reported on a mass change in regimen (to bimatoprost) prompted by a formulary change in which patients were not poor responders to the original medication (latanoprost). We used the opportunity of a formulary change in the Veterans Administration (VA) system to review the consequences of a mass change in therapeutic regimen from latanoprost to travoprost 
in patients with adequate IOP control while on latanoprost. We analyzed medical records from patients in the glaucoma clinic at the Manhattan VA Hospital.

In July 2003, the Veterans Administration (VA) hospital chose to select a single prostaglandin analogue for use within the system. Based on a competitive contracting process, the VA system elected to use travoprost as its primary PGA, and to phase out and eventually totally replace the use of latanoprost. All newly diagnosed glaucoma patients requiring a PGA were to be prescribed travoprost. In order to accommodate potential concerns about tolerability or effectiveness of changing to a new PGA, those patients already on latanoprost were permitted to remain on it at the discretion of their ophthalmologist. No industry support or paid recruitment for a regimen change occurred, however the VA strongly recommended the regimen change to travoprost. In August 2003, the ophthalmologists at the Manhattan VA hospital elected to place all stable glaucoma patients who were prescribed a PGA on travoprost. There was no direct clinical trial experience within the VA hospital system with travoprost. Thus, we had an interest in evaluating if travoprost would be tolerated as well and would be as effective as other PGAs such as latanoprost.

The purpose of this retrospective study was to evaluate the efficacy and tolerability (as defined by changes in IOP and changes in adverse effects, respectively) of travoprost $0.004 \%$ substituted for latanoprost $0.005 \%$ in a glaucoma population undergoing a formulary change at the VA hospital.

\section{Patients and methods}

We conducted a retrospective chart review of patients identified through pharmacy records as being moved from latanoprost $0.005 \%$ to travoprost $0.004 \%$ from August, 2003 through July, 2004 at the Manhattan VA Hospital. The study was approved by the institutional review board (IRB) of the New York Campus of the New York Harbor Healthcare System of the Veterans Administration. In accordance with minimal patient risk, a waiver of consent was obtained from the IRB. A computerized pharmacy dispensing database was accessed, and a printout of those patients was generated. We selected only patients with diagnoses of open angle glaucomas, including primary open angle glaucoma (POAG), pigment dispersion glaucoma (PDG), or pseudoexfoliation glaucoma (PSX), and ocular hypertension (OHT), who were treated in the glaucoma clinic at the Manhattan VA. We excluded uveitis and other disorders that may be associated with IOP fluctuations unrelated to the medication change. Only patients considered stable on the previous medication were included. Patients were considered stable if their IOP values had been within their target range for at least 6 months prior to the switch, and the patients were not being considered for surgery or therapeutic modification outside of the formulary change. Therapeutic regimens prior to the change included latanoprost alone or in combination with other drugs (see Results for specific therapies). No changes in medical regimen, ocular or oral, were permitted during follow-up, other than the change to travoprost. No minimum IOP was required for inclusion in the study.

The primary selection criterion for inclusion into this study was the availability of documentation of patientreported adverse events for all visits during the study. We used a direct questioning survey designed to capture changes in adverse events. Questions drew upon subjective patient assessment of any changes in adverse events, such as hyperemia and irritation (see Appendix). At the baseline visit, patients were specifically asked if they had experienced any adverse events since beginning latanoprost. At all followup visits, they were asked if any changes occurred after changing to travoprost. These responses were documented in the electronic record of each patient. In addition, patients selected for inclusion had to be seen in the VA clinic by one of the doctors and IOP data had to be present in the electronic record for all visits. It should be noted that all patients whose regimen was changed from latanoprost to travoprost were included in the survey, regardless of whether they met the other inclusion criteria which were formulated retrospectively. This was done to ensure the inclusion of all potential patients for subsequent data analysis and help eliminate any inclusion/exclusion bias.

Intraocular pressure was measured by Goldmann tonometry at baseline (prior to the regimen change), at 3 months ( \pm 2 weeks), and at 6 months ( \pm 2 weeks) after the patients received travoprost. Measurements were made by a total of eight to ten observers, as the study was performed within a residency training program. All measurements were performed by third-year residents with training administered by Dr. Farris on the proper method of Goldmann tonometry. The same tonometer was used for every patient at every visit. The tonometer was preset to $20 \mathrm{mmHg}$ prior to any measurements being performed and was calibrated monthly. All measurements were obtained between 12:30 pm and 3:00 pm. We used IOP from both eyes and considered each eye as an independent unit of measurement. 
The primary outcome measures were IOP change between baseline and 6 months and patient-reported adverse events throughout the study.

\section{Results}

The study consisted of 188 eyes of 97 patients. All patients were male. Demographic data are shown in Table 1. The diagnoses for these patients were as follows: POAG $(86 \%)$, OHT (6\%), PSX (6\%), and PDG (2\%). POAG accounted for $71 \%$ of monotherapy patients and $92 \%$ of the concomitant therapy group. The monotherapy group included 60 eyes and the concomitant therapy group 128 eyes. One patient ( 2 eyes) in the concomitant therapy group was switched back to latanoprost at 3 months due to irritation, and thus was not included in final statistical analyses. Due to the small number of patients for whom data were available at 3 months, we elected to omit these data from our final analysis.

In the concomitant therapy group, medications prescribed in addition to latanoprost included: dorzolamide/timolol in 112 eyes (88\%); brimonidine in 94 eyes (73\%); timolol in 13 eyes (10\%); and pilocarpine in 4 eyes (3\%). Regimen details are shown in Table 2.

In the single therapy group ( $\mathrm{N}=60$ eyes), the mean baseline IOP on latanoprost was $15.8 \pm 3.1 \mathrm{mmHg}$ (Figure 1). After 6 months on travoprost the mean IOP was $14.9 \pm 2.5 \mathrm{mmHg}$ $(\mathrm{p}<0.1)$. In the concomitant therapy group $(\mathrm{N}=126$ eyes $)$, the mean baseline IOP on latanoprost and concomitant medications was $16.7 \pm 2.4 \mathrm{mmHg}$ (Figure 2). After 6 months on travoprost and the same concomitant medications, the mean IOP was $15.9 \pm 2.2 \mathrm{mmHg}(\mathrm{p}<0.01)$. Figure 3 shows the combined data for all patients (both monotherapy and concomitant therapy). Six months after the change in regimen, the IOP was reduced by approximately an additional $1 \mathrm{mmHg}(\mathrm{p}<0.001)$. Reductions from baseline IOP are represented in Figure 4. Both the monotherapy and concomitant groups showed statistically significant reductions in IOP from the latanoprost baseline ( $\mathrm{p}$ $\leq 0.001$ ). Figures 5 and 6 are histograms showing responses of individual eyes in terms of decreases/increases in IOP (mmHg). A reduction in IOP of $\geq 3 \mathrm{mmHg}$ occurred in 28 eyes of 21 patients at 6 months. An increase in IOP of $\geq 3 \mathrm{mmHg}$ occurred in 5 eyes of 4 patients at 6 months. In our study it was slightly more likely to achieve a $3 \mathrm{mmHg}$ or more additional reduction in the concomitant group (21 of 126 eyes) than in the monotherapy group ( 7 of 60 eyes).

As noted above, one patient ( 2 eyes) was switched back to latanoprost at 3 months due to irritation. As evaluated by direct questioning survey as described above (see Appendix), no other patients reported changes in adverse events
Table I Demographics and diagnoses

\begin{tabular}{|c|c|}
\hline \multicolumn{2}{|l|}{ Parameter } \\
\hline \multirow[t]{2}{*}{ Mean age in years } & $65 \pm 9.4$ \\
\hline & $\%$ of patients \\
\hline \multicolumn{2}{|l|}{ Ethnicity } \\
\hline Black & 52 \\
\hline Caucasian & 39 \\
\hline Hispanic & 7 \\
\hline Asian & 2 \\
\hline \multicolumn{2}{|l|}{ Diagnosis } \\
\hline Primary open angle glaucoma & 86 \\
\hline Pseudoexfoliation glaucoma & 6 \\
\hline Ocular hypertension & 6 \\
\hline Pigment dispersion glaucoma & 2 \\
\hline
\end{tabular}

compared to the latanoprost baseline, including increased hyperemia, throughout the 6-month follow-up period.

\section{Discussion}

Our study incorporates several features which distinguish it from previous studies. First, the patients in our study were considered stable (with regard to IOP) on latanoprost prior to the change to travoprost therapy. Previous studies have evaluated patients deemed nonresponders or poor responders to latanoprost prior to a regimen substitution (Williams 2002; Kaback et al 2004; Gandolfi and Cimino 2003; Hollo et al 2005).

Second, in many glaucoma and OHT studies, sample size is limited by the exclusion of fellow eye results. There is current debate as to whether or not fellow eyes in glaucoma exhibit concordant IOP changes, response to treatment, and disease progression. Some have used fellow eyes as an internal control (Williams 2002). Others have observed independent risk factors and disease progression between fellow eyes (Levine et al 2006; Chen and Bhandari 2000). Realini and associates have observed variable fellow eye concordance in different studies. Observations from a 2002 study led Realini et al to conclude that the frequency and magnitude of spontaneous asymmetric fluctuations in IOP

Table 2 Concomitant therapy with latanoprost

\begin{tabular}{lll}
\hline \# Eyes & \% Eyes & \\
\hline 81 & 63 & Dorzolamide/timolol and brimonidine \\
29 & 23 & Dorzolamide/timolol \\
6 & 5 & Timolol and brimonidine \\
5 & 4 & Timolol \\
3 & 2 & Brimonidine \\
2 & 2 & Dorzolamide/timolol, brimonidine, and pilocarpine \\
2 & 2 & Timolol, brimonidine, and pilocarpine \\
\hline
\end{tabular}




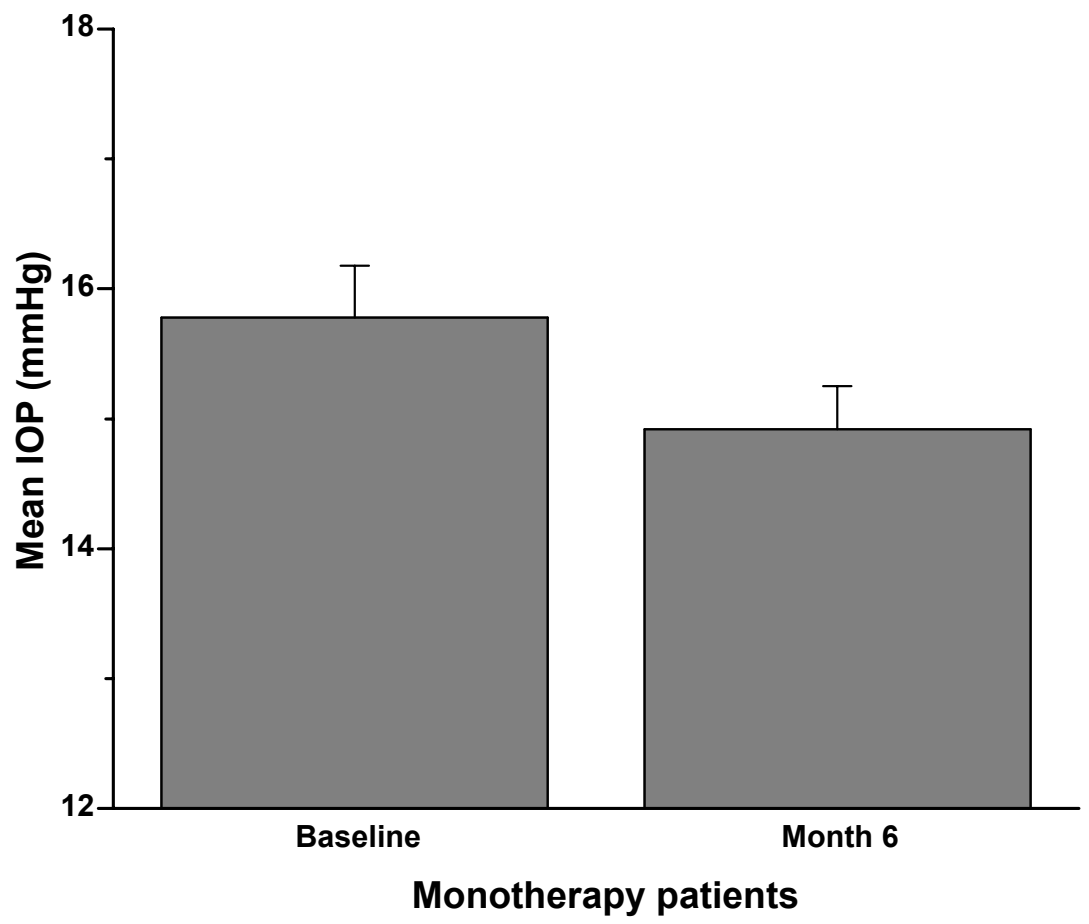

Figure I Monotherapy group: Patients were on latanoprost $0.005 \%$ monotherapy prior to the switch to travoprost $0.004 \%$ monotherapy. Six months after the switch the $\mathrm{IOP}$ was reduced by approximately an additional I $\mathrm{mmHg}($ mean $+\mathrm{SEM}, \mathrm{p}<0 . \mathrm{I} ; \mathrm{n}=60)$.

between fellow eyes in glaucoma patients could potentially confound the interpretation of monocular drug trials (Realini et al 2002). A 2004 study by Realini and colleagues concluded that the response of the second eye to glaucoma medication could not be adequately predicted from the response of the first eye (Realini et al 2004). In contrast, a 2005 study by Realini and Vickers observed marked symmetry in fellow eye IOP response to glaucoma medications (Realini et al 2005).

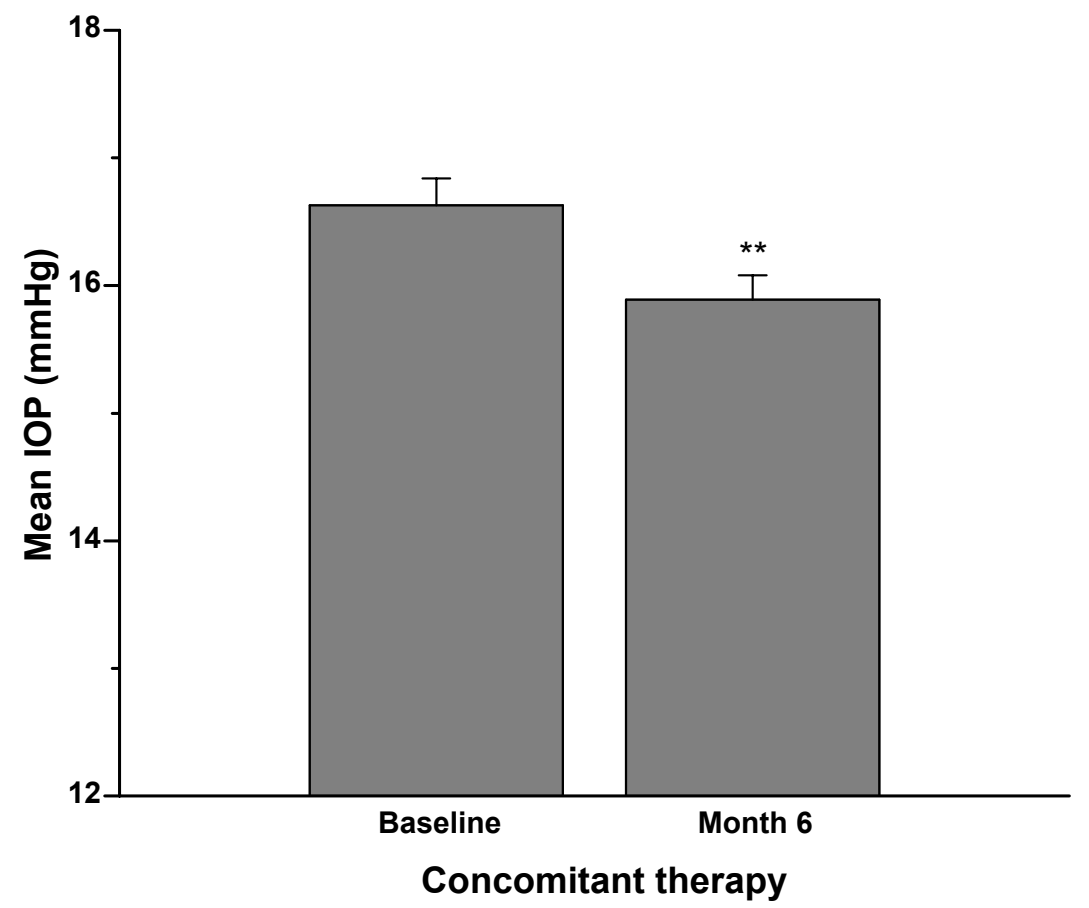

Figure 2 Concomitant therapy group: Patients were on latanoprost $0.005 \%$ plus concomitant therapy prior to the switch to travoprost $0.004 \%$ plus concomitant therapy. Six months after the switch the IOP was reduced by approximately an additional I mmHg (mean + SEM, **p $<0.01 ; n=126)$. 


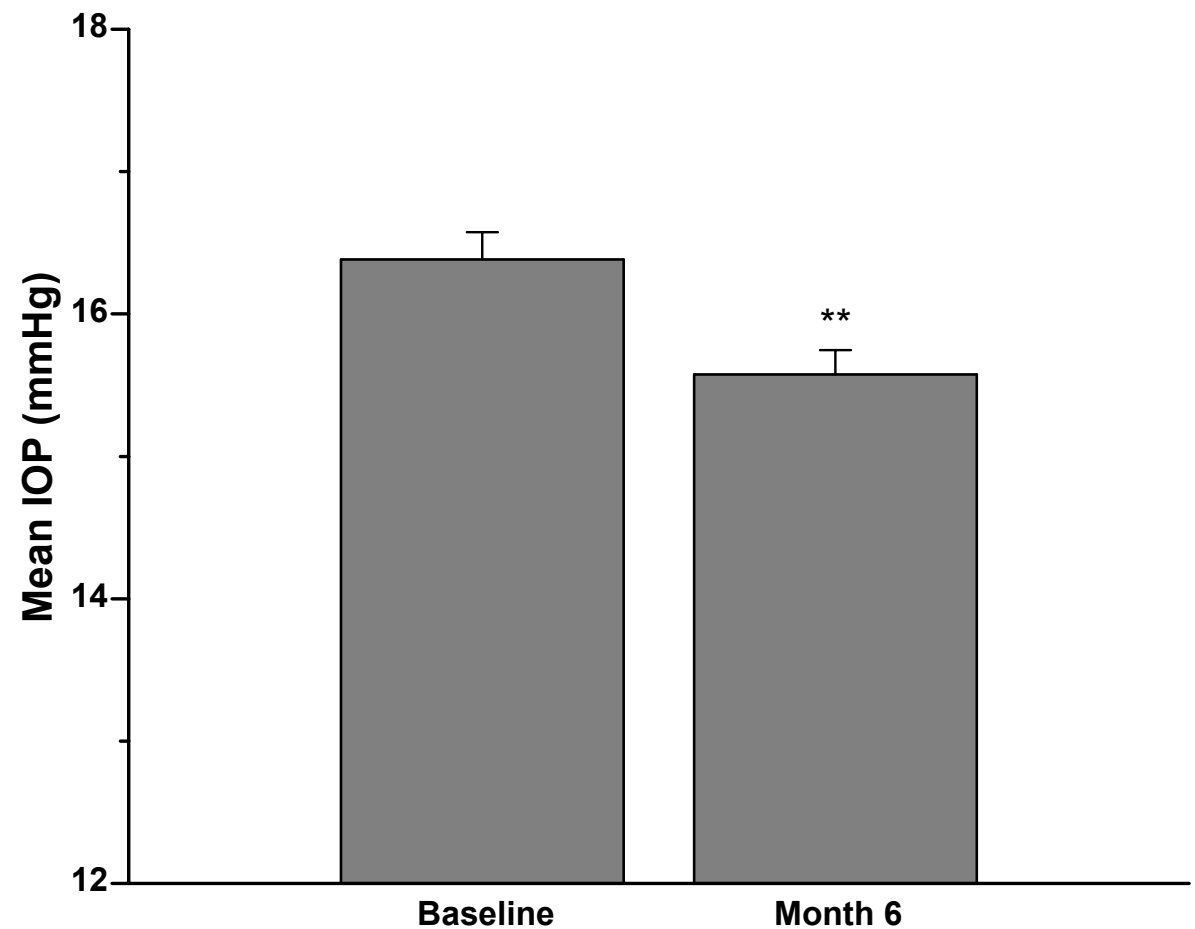

All patients

Figure 3 Patients were on latanoprost $0.005 \%$ monotherapy or latanoprost plus concomitant therapy prior to the switch to travoprost $0.004 \%$. Six months after the switch the IOP was reduced by approximately an additional I $\mathrm{mmHg}\left(\right.$ mean $+\mathrm{SEM}$, $\left.{ }^{* *} \mathrm{p}<0.00 \mathrm{I} ; \mathrm{n}=\mathrm{I} 86\right)$.

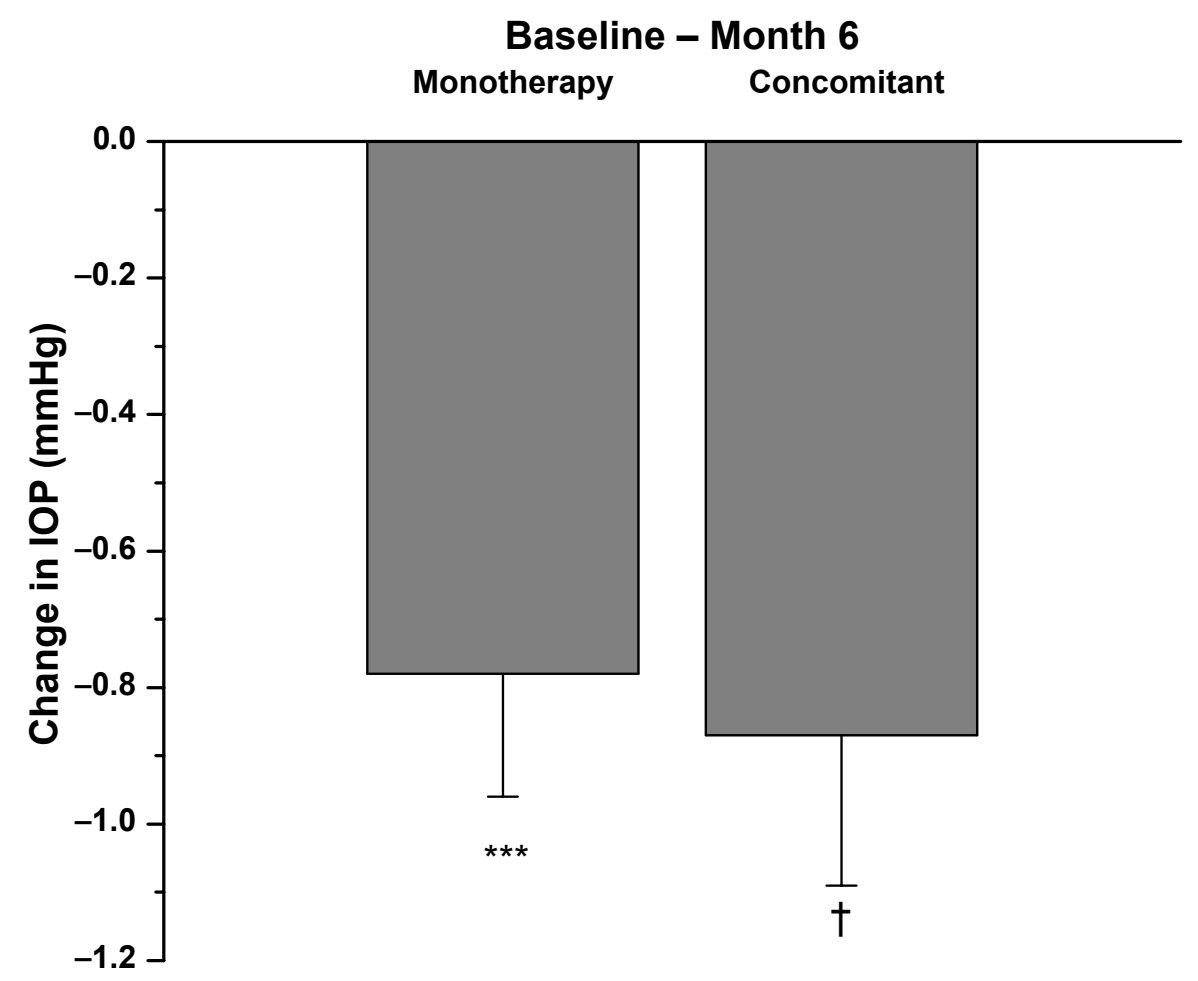

Figure 4 Patients were on latanoprost $0.005 \%$ monotherapy or concomitant therapy prior to the switch to travoprost $0.004 \%$. Data presented are based on the number of eyes with IOP measurement available from the specific visit. Changes = Follow-up IOP - Baseline IOP of the same eye. A negative number indicates a reduction in IOP. The results indicate that in each group, the within-eye IOP changes from pre-switch to 6 months ( $n=60$ monotherapy; $n=126$ concomitant therapy) after switch were statistically significant (mean $+\mathrm{SEM}$, $\left.{ }^{* * *} \mathrm{p}<0.001, \dagger \mathrm{p}<0.000 \mathrm{I}\right)$. 


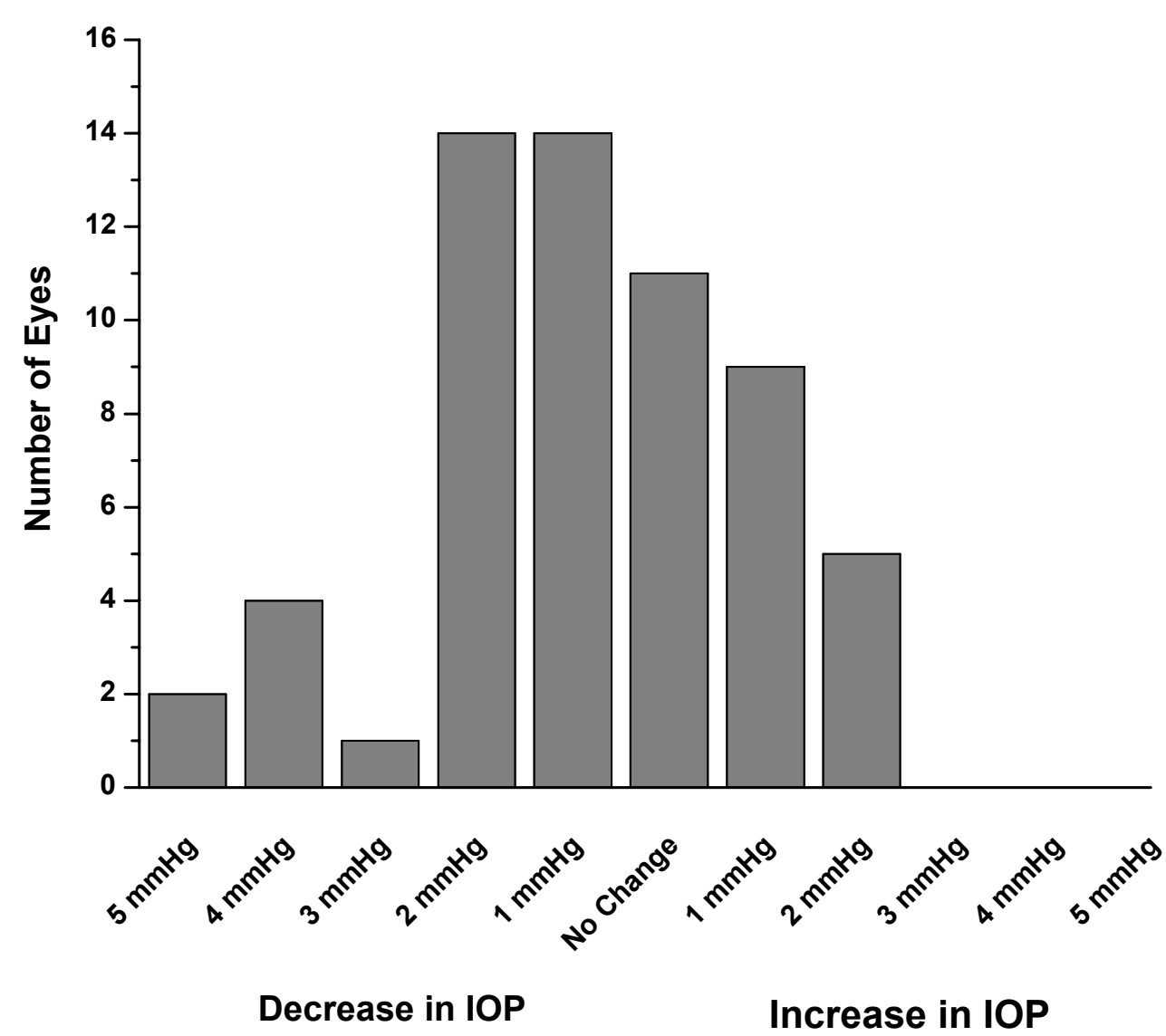

Figure 5 At 6 months, a few patients previously on monotherapy experienced an increase in IOP while several experienced a decrease in IOP of 3 mmHg or more $(\mathrm{n}=60)$.

Recently, Dinn et al observed that the diurnal variation of IOP in POAG is largely concordant between fellow eyes, but that fellow eye IOP may fluctuate asymmetrically a minority of the time (Dinn et al 2007). In view of evidence for independent risk factors and conflicting observations regarding symmetrical response to medication, we chose to consider fellow eyes independently.

The methodology and results of our mass change to travoprost were comparable to those of Law et al (2005) in several ways. Both were nonrandomized analyses of a change from one prostaglandin analogue to another. The medication switch in both studies occurred because of a formulary change rather than inadequate IOP control or side effects.

Of particular interest is our observation that in our patient population IOP control was maintained after switching patients with stable IOP. Furthermore, some patients exhibited a lower IOP on travoprost at the 6-month visit despite previous adequate control with latanoprost. An IOP decrease of an additional $3 \mathrm{mmHg}$ or more occurred in at least one eye of greater than $20 \%$ of patients after switching from latanoprost to travoprost. In our study it was slightly more likely to achieve a $3 \mathrm{mmHg}$ or more additional reduction in the concomitant (21 of 126 eyes) than in the monotherapy (7 of 60 eyes) group. This finding contrasts with the results observed by Law and colleagues, where most patients with $\geq 3 \mathrm{mmHg}$ additional reduction were in the monotherapy group. An increase in IOP $\geq 3 \mathrm{mmHg}$ occurred in 5 eyes of 4 patients, all in the concomitant therapy group. No patient in the monotherapy group showed an increase in IOP $\geq 3$ $\mathrm{mmHg}$ at 6 months. These observations may support the theory that individual patients will have different responses to the medications in the prostaglandin class. Specifically, travoprost has been shown to be a full agonist at the FP receptor while latanoprost is a partial agonist (Griffin et al 1997; Hellberg et al 2002; Sharif et al 2002). This difference in agonist activity could account for the differential responses seen in our study.

Another salient result in our study was that no significant increase in side effects was observed in the 6 month period following the switch to travoprost. In a 12 -week trial involving more than 1000 patients, Przydryga et al (2004) found that $8 \%$ of patients experienced conjunctival hyperemia when switched to travoprost. In contrast, no increase in conjunctival hyperemia was reported by patients at any time after the 


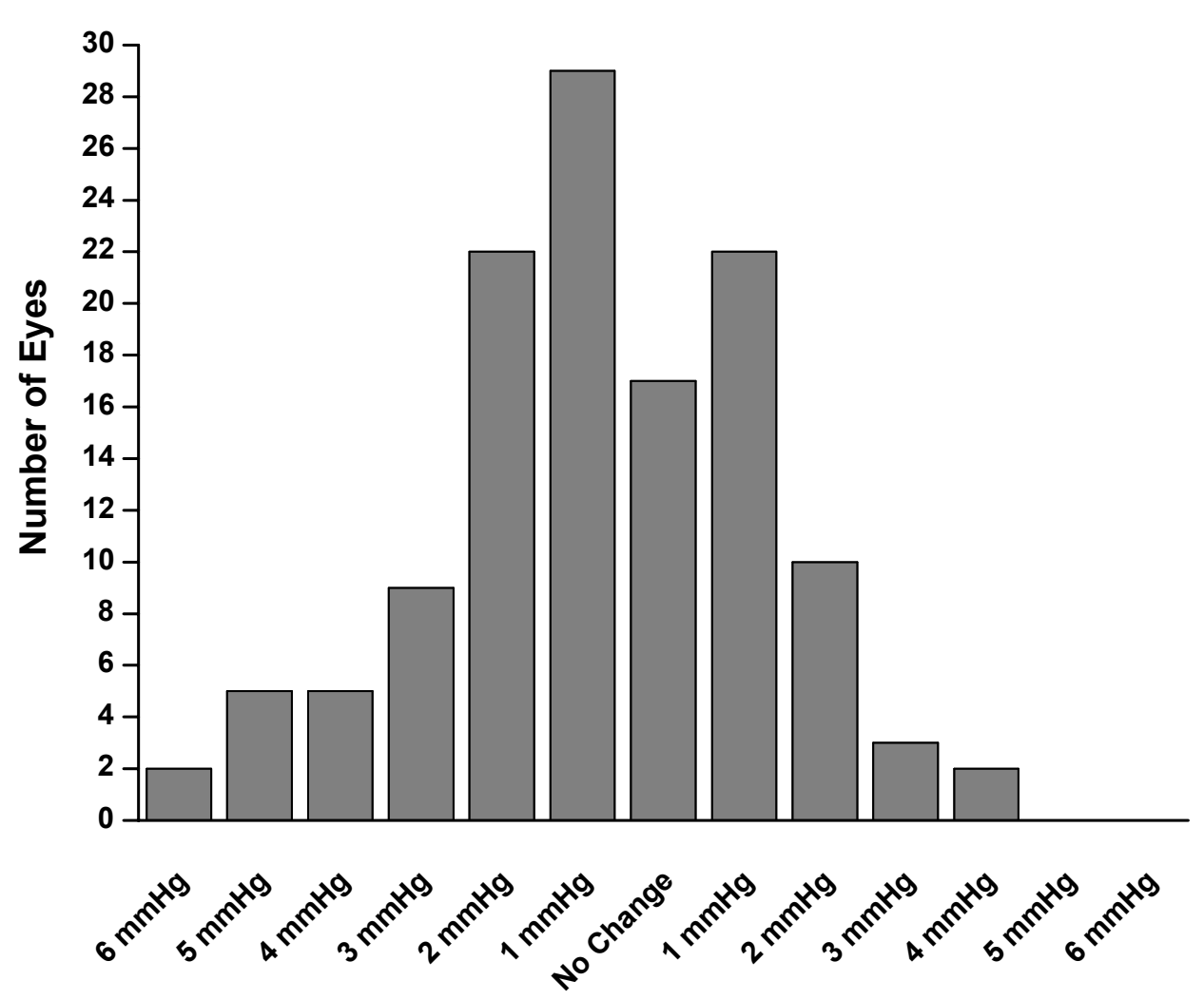

Decrease in IOP

Increase in IOP

Figure 6 At 6 months, a few patients previously on concomitant therapy experienced an increase in IOP while several experienced a decrease in IOP of $3 \mathrm{mmHg}$ or more $(\mathrm{n}=126)$.

switch to travoprost (compared to latanoprost baseline) in our study. One patient (2 eyes) chose to switch back to latanoprost due to irritation at the 3-month visit.

The Early Manifest Glaucoma Trial (EMGT) (Leske et al 2003, 2004) suggested that each mean increase of $1 \mathrm{mmHg}$ in IOP increases by $10 \%$ the risk of visual field deterioration. Further studies are needed to assess the clinical relevance of such small incremental changes in individual patients. Our results include data on decreases of up to $6 \mathrm{mmHg}$ after 6 months on travoprost (see Figures 5 and 6). The change seen in mean IOP in both groups is statistically significant, and may also be clinically relevant. However, we recognize that the most likely cause of the statistically significant mean IOP reduction is the number of patients whose IOP was lowered greater than $3 \mathrm{mmHg}$ compared to those whose IOP rose greater than $3 \mathrm{mmHg}$. Therefore, in our study, a change in regimen from latanoprost to travoprost resulted in minimal change in IOP for most patients; however, a significant lowering of IOP was seen in some patients at 6 months. Few to none exhibited a significant rise in IOP which would prompt a further change in regimen.
The occurrence of further IOP decreases with travoprost in patients who were already controlled is intriguing. Maintenance of control and the absence of significant side effects (notably the absence of increased hyperemia) conferred no disadvantage to a substitution to travoprost in our study. In addition, the change in therapeutic regimen provided the opportunity to optimize control.

The nature of data collection subjects this study to several limitations. First, patients were sequentially, not randomly selected. However, patients selected for inclusion in the study are typical of those seen in clinical practice in regard to such factors as age, disease state, and potential for benefiting from medical intervention. In addition, circumstances of the therapeutic substitution such as the lack of a washout phase of the previous medication are typical of everyday clinical practice. Because the study was conducted at the VA, a predominantly male population, no female patients were included. No data on gender variation of PGA response are available, however there is no reason to suspect that such variation exists. Thus, the study patients are in many ways representative of the population to which the results will be applied. 
In addition to non-randomization, the study was openlabel, thus presenting the possibility that participants were influenced toward better compliance. However, such assessment bias was likely minimal because patients knew their medication was being substituted purely due to a change in formulary. In accordance with minimal patient risk, a waiver of consent had been obtained from the IRB, and patients were aware that the new medication was not required due to medication failure or advancing disease. Thus patient motivation for better compliance seems unlikely. Another limitation posed by our evaluation is the inclusion of multiple observers. Inter-observer differences in technique could account for some changes in IOP, and these potential differences are difficult to analyze separately. However, intra- and inter-observer variation have been reported to range from less than $1 \mathrm{mmHg}$ to more than $3 \mathrm{mmHg}$ (Sudesh et al 1993; Dielemans et al 1994; Kaufman et al 2004; Tonnu et al 2005). In addition, inter-observer differences were at least partially offset by the fact that all observers were third-year residents with similar training administered by Dr. Farris on the proper method of Goldmann tonometry. The same tonometer was used for every patient at every visit. The tonometer was preset to $20 \mathrm{mmHg}$ prior to any measurements being performed and was calibrated monthly. Moreover, it is unlikely that most differences introduced by inter-observer variation would fall in the same direction and account for the statistically significant results obtained in our study. A further limitation of the study was observation of a single IOP at all study points. Diurnal variation was minimized, however, by measuring all IOP within a 3-hour window in the afternoon. It seems unlikely that any of the above limitations could account for the high percentage of patients with a decrease in IOP versus the low percentage with an increase after the regimen change.

\section{Conclusions}

A large scale change in regimen from latanoprost $0.005 \%$ to travoprost $0.004 \%$ maintained IOP control in stable patients and in some produced a further reduction in IOP. Reductions from baseline occurred at 6 months in the monotherapy and concomitant groups. There were no patient-reported events of increased hyperemia throughout 6 months of treatment. A change in therapy from latanoprost to travoprost was effective and well-tolerated for the glaucoma patients in this study.

\section{Acknowledgments}

The author acknowledges the contributions of Rhonda R. Porterfield, MD, Julie Y. Crider, PhD, and Jenny Song,
MS for medical writing, editing, and statistical analyses, respectively. Publication support was provided by Alcon Laboratories, Inc.

\section{References}

Camras CB. 1995. Mechanism of the prostaglandin-induced reduction of intraocular pressure in humans. Adv Prostaglandin Thromboxane Leukot Res, 23:519-25.

Chen PP, Bhandari A. 2000. Fellow eye prognosis in patients with severe visual field loss in 1 eye from chronic open-angle glaucoma. Arch Ophthalmol, 118:473-8.

Crawford K, Kaufman PL. 1987. Pilocarpine antagonizes prostaglandin F2 alpha-induced ocular hypotension in monkeys. Evidence for enhancement of uveoscleral outflow by prostaglandin F2 alpha. Arch Ophthalmol, 105:1112-16.

Dielemans I, Vingerling JR, Hofman A, et al. 1994. Reliability of intraocular pressure measurement with the Goldmann applanation tonometer in epidemiological studies. Graefes Arch Clin Exp Ophthalmol, 232:141-4.

Dinn RB, Zimmerman MB, Shuba LM, et al. 2007. Concordance of diurnal intraocular pressure between fellow eyes in primary open-angle glaucoma. Ophthalmology, 114:915-20.

Gabelt BT, Kaufman PL. 1989. Prostaglandin F2 alpha increases uveoscleral outflow in the cynomolgus monkey. Exp Eye Res, 49:389-402.

Gandolfi SA, Cimino L. 2003. Effect of bimatoprost on patients with primary open-angle glaucoma or ocular hypertension who are nonresponders to latanoprost. Ophthalmology, 110:609-14.

Griffin BW, Williams GW, Crider JY, et al. 1997. FP prostaglandin receptors mediating inositol phosphates generation and calcium mobilization in swiss 3T3 cells: a pharmacological study. J Pharmacol Exp Ther, 281:845-54.

Hellberg MR, McLaughlin MA, Sharif NA, et al. 2002. Identification and characterization of the ocular hypotensive efficacy of travoprost, a potent and selective FP prostaglandin receptor agonist, and AL-6598, a DP prostaglandin receptor agonist. Surv Ophthalmol, 47(Suppl 1):S13-33.

Hollo G, Vargha P, Kothy P. 2005. Influence of switching to travoprost on intraocular pressure of uncontrolled chronic open-angle glaucoma patients compliant to previously-used topical medication. Curr Med Res Opin, 21:1943-8.

Kaback M, Geanon J, Katz G, et al; START Study Group. 2004. Ocular hypotensive efficacy of travoprost in patients unsuccessfully treated with latanoprost. Curr Med Res Opin, 20:1341-5.

Kaufmann C, Bachmann LM, Thiel MA. 2004. Comparison of dynamic contour tonometry with goldmann applanation tonometry. Invest Ophthalmol Vis Sci, 45:3118-21.

Law SK, Song BJ, Fang E, et al. 2005. Feasibility and efficacy of a mass switch from latanoprost to bimatoprost in glaucoma patients in a prepaid Health Maintenance Organization. Ophthalmology, 112:2123-30.

Leske MC, Heijl A, Hussein M, et al. 2003. Early Manifest Glaucoma Trial Group. Factors for glaucoma progression and the effect of treatment: the early manifest glaucoma trial. Arch Ophthalmol, 121:48-56.

Leske MC, Heijl A, Hyman L, et al. 2004. Factors for progression and glaucoma treatment: the Early Manifest Glaucoma Trial. Curr Opin Ophthalmol, 15:102-6.

Levine RA, Demirel S, Fan J, et al; Ocular Hypertension Treatment Study Group. 2006. Asymmetries and visual field summaries as predictors of glaucoma in the ocular hypertension treatment study. Invest Ophthalmol Vis Sci, 47:3896-903.

Nilsson SF, Samuelsson M, Bill A, et al. 1989. Increased uveoscleral outflow as a possible mechanism of ocular hypotension caused by prostaglandin F2 alpha-1-isopropylester in the cynomolgus monkey. Exp Eye Res, 48:707-16.

Przydryga JT, EgloffC, and Swiss Start Study Group. 2004. Intraocular pressure lowering efficacy of travoprost. Eur J Ophthalmol, 14:416-22.

Realini T, Barber L, Burton D. 2002. Frequency of asymmetric intraocular pressure fluctuations among patients with and without glaucoma. Ophthalmology, 109:1367-71. 
Realini T, Fechtner RD, Atreides SP, et al. 2004. The uniocular drug trial and second-eye response to glaucoma medications. Ophthalmology, 111:421-6.

Realini T, Vickers WR. 2005. Symmetry of fellow-eye intraocular pressure responses to topical glaucoma medications. Ophthalmology, 112:599-602.

Sharif NA, Kelly CR, Crider JY. 2002. Agonist activity of bimatoprost, travoprost, latanoprost, unoprostone isopropyl ester and other prostaglandin analogs at the cloned human ciliary body FP prostaglandin receptor. J Ocul Pharmacol Ther, 18:313-24.
Sudesh S, Moseley MJ, Thompson JR. 1993. Accuracy of Goldmann tonometry in clinical practice. Acta Ophthalmol (Copenh), 71:185-8.

Tonnu PA, Ho T, Sharma K, et al. 2005. A comparison of four methods of tonometry: method agreement and interobserver variability. Br J Ophthalmol, 89:847-50.

Williams RD. 2002. Efficacy of bimatoprost in glaucoma and ocular hypertension unresponsive to latanoprost. Adv Ther, 19:275-81. 


\section{Appendix}

Patient Survey

Patients were asked the following questions before and after the change in regimen from latanoprost to travoprost. Answers were recorded in the patients' medical record.

Questions at baseline:

Do you experience any stinging/burning/irritation when placing your latanoprost drop?

Yes/No

Have you noticed an increase in the length of eyelashes since beginning latanoprost?

Yes/No

Have you noticed an increase in the darkness around your eyes since beginning latanoprost?

Yes/No

Has there been any change in the color of your eyes since beginning latanoprost?

Yes/No
Have you noticed any increase in eye redness since beginning latanoprost?

Yes/No

Questions at follow-up:

Have you noticed any increase or decrease in stinging/burning/irritation since the switch to travoprost? Identify/None

Have you noticed any increase in eyelash length since the switch to travoprost?

$\mathrm{Yes} / \mathrm{No}$

Have you noticed any increase in darkness around your eyes since the switch to travoprost?

Yes/No

Have you noticed any change in the color of your eyes since the switch to travoprost?

$\mathrm{Yes} / \mathrm{No}$

Has there been any increase in eye redness since the switch to travoprost?

Yes/No 